\title{
TWO NEW SPECIES OF ZAISCHNOPSIS ASHMEAD (HYMENOPTERA: EUPELMIDAE) FROM SOUTHERN INDIA AND A KEY TO ORIENTAL SPECIES
}

\author{
T.C. Narendran ${ }^{1,2}$, S. Santhosh ${ }^{2}$, Abhilash Peter ${ }^{2}$, M.C. Jilcy ${ }^{2}$ and P.V. Anitha ${ }^{2}$ \\ Systematic Entomology Laboratory, Department of Zoology, University of Calicut, Kerala 673635, India \\ Email: ${ }^{1}$ drtcnarendran@yahoo.com
}

\begin{abstract}
The genus Zaischnopsis Ashmead is represented in India by three species viz. Zaischnopsis biharensis (Narendran) including the two new species described in this paper, viz., Zaischnopsis keralensis Narendran sp. nov. and Zaischnopsis bathericus Narendran sp. nov. Comparative accounts of the two new species and the diagnostic features of $Z$. biharensis (Narendran) are given. A key to the Oriental species of Zaischnopsis is also included.

\section{KEYWORDS}

Chalcidoidea, Eupelmidae, key, new species, oriental region, taxonomy, Zaischnopsis bathericus Narendran sp. nov., Zaischnopsis keralensis Narendran sp. nov.

Abbreviations

DZUC - Department of Zoology, University of Calicut; F1-F8 - Funicular segments 1 to 8 [anellus is considered here as F1]; MV - Marginal vein; OOL - Ocellocular distance; PMV Postmarginal vein; POL - Postocellar distance; SMV Submarginal vein; STV - Stigmal vein; T1-T6 - Gastral tergites 1 to 6; ZSIK - Western Ghats Regional Station, Zoological Survey of India, Kozhikode.
\end{abstract}

The genus Zaischnopsis was erected by Ashmead (1986) under the name Ischnopsis with type species Ischnopsis opthalmica Ashmead. Since the name Ischnopsis was already preoccupied by Ischnopsis Walsingham (Walsingham, 1881), Ashmead (1904) later provided a replacement name Zaischnopsis for Ischnopsis Ashmead. Bouèek (1988) synonymized Zaischnopsis with Anastatus Motschulsky. Gibson (1995) reestablished the generic status of Zaischnopsis Ashmead. He also synonymised Eupelmoides Masi (1917) with Zaischnopsis. The genus Zaischnopsis contains 25 species in the world and six species in the Oriental region (Gibson, 2005; Girault, 1915, 1919; Walker, 1852, 1862). From India so far only one species is reported (Narendran et al., 2004; Gibson, 2005). In this paper, two new species viz. Zaischnopsis keralensis Narendran sp. nov. and Zaischnopsis bathericus Narendran sp. nov are described, with a review of the Indian species. A key to separate Oriental species of Zaischnopsis is also provided. The holotype of the new species described here are deposited in the DZUC, but eventually will be transferred to ZSIK at a later stage. (The type of Zaischnopsis biharensis (Narendran) already deposited in the DZUC will also be transferred to ZSIK).

\section{ZAISCHNOPSIS KERALENSIS Narendran sp. nov.}

$$
\text { (Figs. 1-6) }
$$

\section{Material examined}

Holotype: Female, 10.i.2004, Cheruthoni $\left(9^{\circ} 51^{\prime} \mathrm{N}-76^{\circ} 58^{\prime} \mathrm{E}\right)$, Idukki District, Kerala, coll. T.C. Narendran \& Party, DZUC

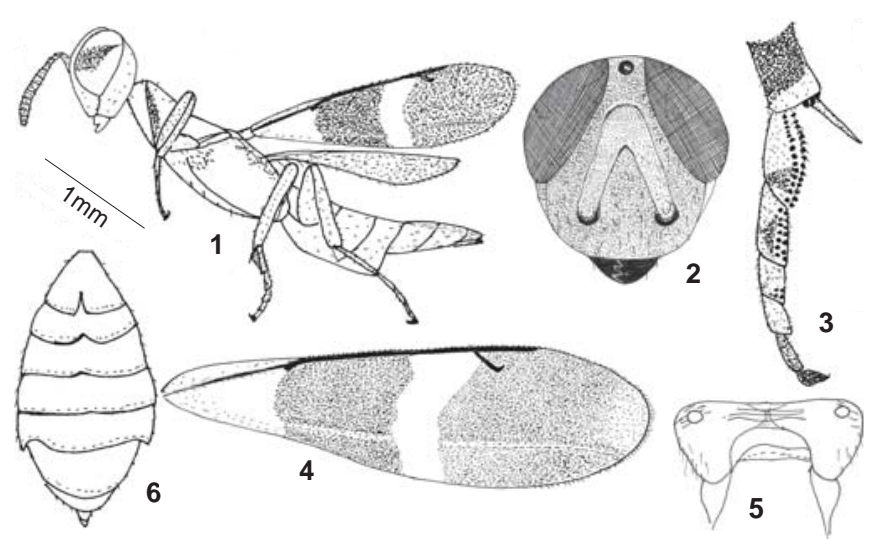

Figures 1-6. Zaischnopsis keralensis Narendran sp. nov. (Female); 1 - Body profile; 2 - Head front view; 3 - Apex of midtibia with tarsi; 4 - Forewing; 5 - Propodeum; 6 - Gaster dorsal view

Reg. No. MoEF 339.

\section{Distribution}

Known only from Idukki District of Kerala state, India.

\section{Etymology}

The species epithet is after the name of the state Kerala from where it is collected.

\section{Description}

Female: Length including ovipositor sheath $3.6 \mathrm{~mm}$. Head slightly dark with metallic green lustre. Palpi dark brown. Mandible dark brown with base slightly paler. Antenna black with metallic green lustre on scape, pedicel, anellus and F1. Mesosoma dark with metallic green lustre on dorsum and sides of pronotum. Legs black with following yellowish to white: metatarsi and following three tarsi of mid and hind legs with apical pegs of midtibia and tarsi black. Forewing infuscate beyond base of parastigma except for a hyaline cross band extending from MV to posterior margin, infuscation slightly lighter at apical part of forewing. Gaster black without any metallic lustre.

Head: Scrobal depression with distinct dorsal margin separated from anterior ocellus by a distance equal to $2 \mathrm{x}$ diameter of front ocellus (Fig. 2); channel and scrobes strongly reticulate to transversely reticulate strigose; frons strongly reticulate, interantennal region strongly reticulate, with sparse setae. Lower parascrobal region with scattered white setae not differentiated from other setae on face. Frontovertex strongly

Manuscript 1676; (C) ZOO; Date of publication 21 May 2007 Received 15 November 2006; Revised received 31 January 2007; Finally accepted 23 April 2007 
reticulate from scrobal channel to posterior ocelli, without distinct setae. Vertex angled relative to comparatively flat and extensive occiput at level of anterior margin of posterior ocelli and both vertex and occiput coriaceous-reticulate with short pale white setae. Gena posterior to malar sulcus strongly and longitudinally striate-reticulate with conspicuous white lanceolate scattered setae. Antenna (Fig. 1) with scape strongly reticulate-strigose on outer and inner sides; flagellum elongate, increasing width towards clava with apical three funicular segments transverse.

Mesosoma: Pronotum with median furrow deep; mesoscutum entirely striate-reticulate, sparsely setose; setae white and lanceolate (without any dark hair-like setae). Scutellar-axillar complex punctate-reticulate. Acropleuron anteriorly with white lanceolate setae in triangular region. Metacoxa with dense, lanceolate white setae ventrolaterally and dorsally (without clear cut bare median longitudinal area). Propodeum (Fig. 5) with callus broadly bare posterior to spiracle, but setose anterior to and mesal to spiracle and with dense white setae postero-laterally. Forewing 3.33x as long as wide; relative lengths of veins: $\mathrm{SMV}=46 ; \mathrm{MV}=58$; $\mathrm{PMV}=$ 20; $\mathrm{STV}=10$.

Gaster: A little longer than mesosoma (59: 54), syntergum mostly covered by preceding tergum. Ovipositor sheath exserted only very slightly beyond syntergal flange.

\section{Remarks}

Biology unknown. This new species differs from the other Indian species $Z$. biharensis Narendran by the differences mentioned under the species Z. biharensis in this paper below. There are four species known from South East Asia and one from Hong Kong, China. They differ from this new species in the following characters:

Z. cooki (Girault) differs from this new species in having: (i) F6 and clava white; (ii) PMV longer than MV; (iii) All of dorsum of mesosoma except sides narrowly of scutellum black.

Z. magniscapus (Girault) differs in having: (i) Scape foliaceously dilated; (ii) Gaster completely metallic; (iii) F2 and F4 equal in size; and (iv) F1 quadrate.

Z. locustae (Girault) differs in having: (i) F2 to F4 equal in size; (ii) Longest funicular segment 3x longer than F1; (iii) F8 nearly square; and (iv) Middle tibial spur metallic.

Z. fascipennis (Walker) differs in having: (i) MV a little shorter than SMV; and (ii) Gaster metallic copper red varied with green.

Z. tubatius (Walker) differs in having: (i) Midtibial spur black; and (ii) Gaster purple coloured.

\section{ZAISCHNOPSIS BIHARENSIS (Narendran) \\ (Figs. 7-9)}

Anastatus biharensis Narendran, Narendran et al. 2004: 16-18, Female, India (DZUC Reg. No. Eu 337).

Zaischnopsis biharensis (Narendran), Gibson, 2005: 109.

\section{Diagnosis}

This species differs from Z. keralensis Narendran sp. nov. in having: (i) Forewing with two hyaline spots or patches instead

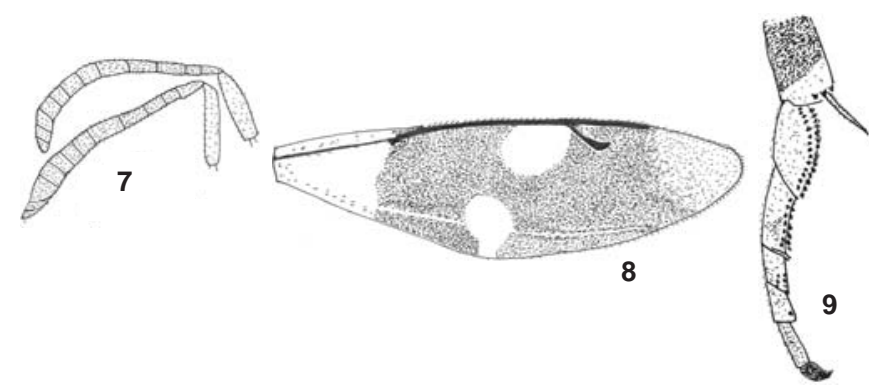

Figures 7-9. Zaischnopsis biharensis (Narendran) 7 - Antenna; 8 - Apex of midtibia; 9 - Forewing

of a single continuous median band (Fig. 9); (ii) Front ocellus separated from scrobe by its own diameter; and (iii) Different proportion of antennal segments.

Z. cooki (Girault) differs from Z. biharensis (Narendran) in having: (i) F6 and clava white; (ii) PMV longer than MV; and (iii) All of dorsum of mesosoma except sides of scutellum narrowly black.

Z. magniscapus differs in having: (i) Different proportion of antennal segments; (ii) Mesoscutum without a raised median area; and (iii) Middle tibial spur black.

Z. locustae (Girault) differs from Z. biharensis in having: (i) F2 to $\mathrm{F} 4$ equal in length; (ii) Longest funicular segment $3 \mathrm{x}$ longer than F1; (iii) Pedicel as long as F3; and (iv) Middle tibial spur metallic.

Z. fascipennis (Walker) differs in having: 1) MV a little shorter than SMV; 2) Gaster metallic copper red, varied with green.

Z. tubatius (Walker) differs in having: 1) Midtibial spur black; 2) Legs copper colour and 3) Forewing as in Z. keralensis.

In the original description, it is wrongly stated that $\mathrm{T} 2$ is longer than $\mathrm{T} 3$ in $Z$. biharensis which is actually vice versa (T3 is longer than T2). The same is corrected here.

\section{ZAISCHNOPSIS BATHERICUS Narendran sp. nov.}

(Figs. 10-13)

\section{Material examined}

Holotype: Female, 6.v.2000, Sultan's Battery $\left(11^{\circ} 40^{\prime} \mathrm{N}-\right.$ $\left.76^{\circ} 17^{\prime} \mathrm{E}\right)$, Wyanad district, Kerala, coll. T.C. Narendran \& Party, DZUC Reg. No. Moef. 1637.

\section{Distribution}

Known only from Sultan's Battery in Wyanad district, Kerala

\section{Etymology}

The species epithet is after the popular name of the collection locality Sulthan Batheri originally named Sultan's Battery.

\section{Description}

Female: Length including ovipositor sheath $3.1 \mathrm{~mm}$. Head dark with metallic green lustre. Palpi dark brown. Mandibles brown with teeth black. Antenna black with metallic green lustre on scape, pedicel, anellus and F1. Mesosoma dark with 


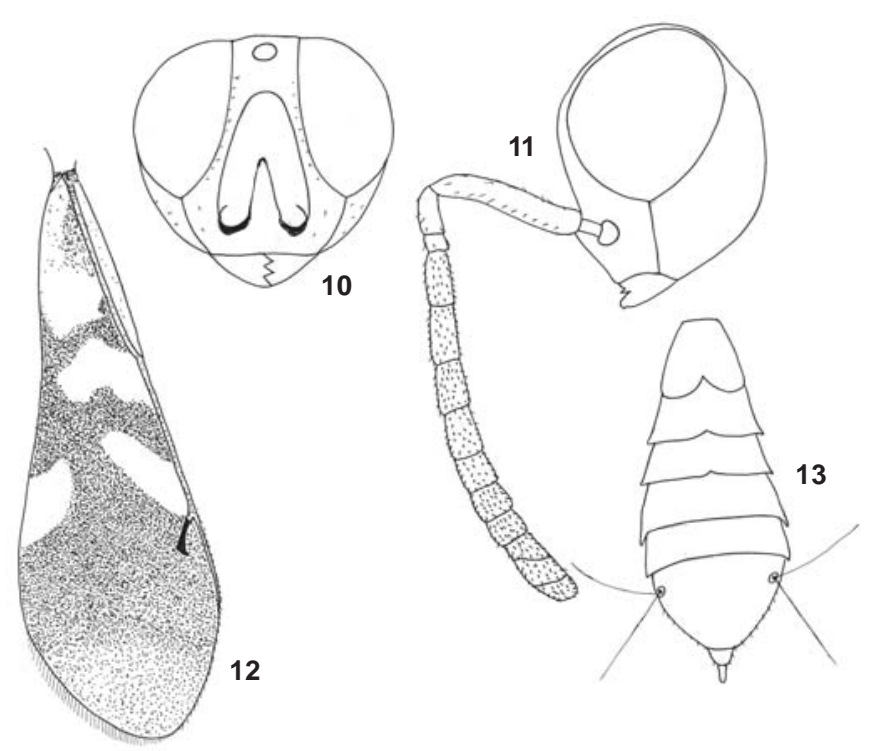

Figures 10-13. Zaischnopsis bathericus Narendran sp.nov. (Female)

10 - Head front view; 11 - Head and antenna side view; 12 - Forewing; 13 - Gaster dorsal view

metallic green lustres on dorsum and sides of pronotum; anterior part of prosomal median furrow pale yellow. Legs black with following parts yellowish-white: apex of mid tibia, apex of hind coxa, hind trochanter, base of hind femur; basal half and apical one third of hind tibia (with a black band in between) and all tarsi of all legs (except black pegs of apex of tibia and of tarsi). Forewing infuscate beyond base of parastigma except for hyaline patches attached to MV and one below anterior patch attached to MV (Fig. 12), hyaline patch attached to base of MV with brown pilosity; pilosity on rest of distal two patches white. Gaster black.

Head: Scrobal depression with distinct dorsal margin separated from anterior ocellus by $1.5 \mathrm{x}$ diameter of front ocellus; scrobe strongly reticulate to transversely reticulatestrigose; frons strongly reticulate, interantennal region strongly reticulate with sparse setae on side margins. Lower parascrobal region with sparse setae. Gena posterior to malar sulcus strongly and longitudinally striate reticulate with scattered pale setae. Antenna (Fig. 11) with scape strongly reticulate-strigose on outer and inner side; flagellum elongate, increasing in width towards clava.

Mesosoma: Pronotum with deep median furrow; mesoscutum entirely reticulate - striate, moderately setose, setae white and lanceolate. Scutellar axillar complex punctatereticulate, Acropleuron anteriorly without white lanceolate setae in a triangular region as in Z. keralensis. Metacoxa with dense, lanceolate, white setae ventro-laterally and dorsally with a clear cut median longitudinal concave cross reticulate area. Propodeum with callus broadly bare posterior to spiracle, but densely setose in posterolateral part. Forewing $2.9 \mathrm{x}$ as long as wide; relative lengths of veins: $\mathrm{SMV}=48$; $\mathrm{MV}=44$; $\mathrm{PMV}=24 ; \mathrm{STV}=9$.

Gaster: (Fig. 13) 1.3x as long as mesosoma in dorsal view (20:26); syntergum covered by preceding tergum, each cerci with two relatively long setae; ovipositor sheath exerted a little beyond syntergal flange.

\section{Key to Oriental species of Zaischnopsis Ashmead}

1. F6 and clava white; F3 to F5 brown; PMV longer than MV which is "punctiform"; STV longer than PMV; dorsum of mesosoma except sides narrowly of scutellum black ..................................................... Z. cooki (Girault)

Characters not as above; partly or completely different 2

2. Scape foliaceously dilated; gaster completely metallic; F2 - F4 equal in size, 2x longer than wide; F1 quadrate; mesoscutum without a raised median area but with a median carina; middle tibial spur black, atleast at base ........ Z. magniscapus (Girault)

Characters not as in above combination; partly or completely different

3

3. F2 to F4 equal, longest funicular segment 3x longer than F1 which is subquadrate; F5 and F6 longer than wide; F8 nearly square; pedicel as long as F3; PMV 2x as long as STV; middle tibial spur metallic; raised triangle of 'cephalic' scutum (= mesoscutum) about one-third surface, with a nearly complete median carina from it; coxae, femora and most of tibiae with metallic lustre; host: eggs of locusts Z. locustae (Girault)

-- $\quad$ Characters not as above, partly or completely different

4

4. Gaster cupreous, lanceolate, varied with green; head black with bluish green reflection on lower part; hind femur completely dark brown (hind tibia similar to bathericus); MV a little shorter than SMV,

Characters partly or completely different from above alternate Z. fascipennis (Walker) (= Z. bifasciatus (Walker)

5. Midtibial spur black; legs copper coloured; (Forewing as in Z. keralensis)

-- Midtibial spur yellow or pale yellow or whitish yellow ...........

Z. tubatius (Walker)

-- $\quad$ Forewing with single hyaline cross band in the middle (Fig.4) 7

7. Forewing with an opaque hyaline spot near base of MV; F6 wider than long; clava longer than combined length

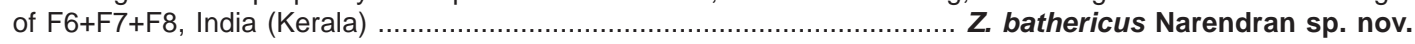
Forewing without an opaque hyaline spot near base of MV; middle hyaline spot not as above; F6 longer than wide; clava shorter than combined length of F6 + F7 + F8, India (Bihar) ..................... Z. biharensis (Narendran)

[The above key is mainly based on literature except for the Indian species] 


\section{Remarks}

Biology unknown. This new species resembles Z. keralensis Narendran sp. nov. in general appearance but differs from it in having: (i) MV shorter than SMV; (ii) Hind tibia with yellow with a black band between an apical half; (iii) Forewing with an opaque hyaline patch near base of MV; (iv) Middle hyaline patches obliquely directed; and (v) Acropleuron without white patch of setae in a triangular region on anterior side.

This species differs from Z. biharensis Narendran in having: (i) MV shorter than SMV; (ii) F6 broader than long; (iii) Forewing with opaque hyaline spots in middle; (iv) MV with an opaque hyaline patch near its base; and (v) Front ocellus separated from scrobe by $1.5 \mathrm{x}$ diameter of front ocellus.

This new species differs from Z. fascipennis (Walker) in having: (i) Gaster not cupreous; (ii) Hind femur black with base yellow (whereas in fascipennis hind femur completely dark brown. This species resembles Z. fascipennis in having: MV shorter than SMV and in similar colouration of hind tibia.

\section{REFERENCES}

Ashmead, W.H. (1896). On the genera of Eupelminae. Proceedings of the Entomological Society of Washington 4: 4-20.

Ashmead, W.H. (1904). New generic names in Chalcidoidea. Proceedings of the Entomological Society of Washington 6: 126.

Bouèek, Z. (1988). Australasian Chalcidoidea (Hymenoptera). A Biosystematic Revision of Fourteen Families with a Classification of Families. CAB
International, Wallingford, 832pp

Gibson, G.A.P. (1995). Parasitic wasps of the subfamily Eupelminae: Classification and revision of World genera (Hymenoptera: Chalcidoidea: Eupelmidae). Memoirs on Entomology, International 5: 421pp.

Gibson, G.A.P. (2005). The species of Zaischnopsis of America north of Mexico, with a checklist of described world species (Hymenoptera Eupelmidae). Acta societatis Zoologicae Bohemoslovenicae 69: 89-112.

Girault, A.A. (1915). Australian Hymenoptera Chalcidoidea - VII. The family Encyrtidae with descriptions of new genera and species. Memoirs of the Queensland Museum 4: 1-184.

Girault, A.A. (1919). Javanese Chalcid flies. Treubia 1: 53-59.

Masi, L. (1917). Chalcididae of the Seychelles Islands. Novitates Zoologicae 24: 121-230.

Narendran, T.C., P.V. Anitha \& K. Kumar (2004). On a new species of Anastatus Motschulsky (Hymenoptera: Eupelmidae) associated with lac insects in Bihar, India. Journal of Advanced Zoology 25: 16-18.

Walker, F. (1852). VI - Notes on Chalcidites and descriptions of various new species. Annals and Magazine of Natural History (2)9: 39-43.

Walker, F. (1862). Notes on Chalcidites and characters of undescribed species. Transactions of Entomological Society of Londoan (3)1: 345-397. Walsingham, L. (1881). On the Tortricidae, Tineidae and Pterophoridae of South Africa. Transactions of the Entomological Society of London, England pp. 71-88.

\section{ACKNOWLEDGeMents}

We are grateful to Ministry of Environment \& Forests, Government of India, for financial assistance for undertaking this research project. We are also grateful to the University of Calicut for facilities to work.

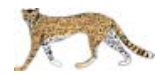

\section{Bombay Natural History Society}

\section{Study of Bird Hazard \& Remedial Measures in Airfieds / Flight Safety Project}

BNHS, India's largest NGO and a scientific research organisation engaged in conservation of nature, natural resources, protection of wildlife and environment through action based on research, education and public awareness - requires:

\section{Ornithologist}

Educational Qualifications: M.Sc. 1st Class in Ornithology/Zoology/ Wildlife biology/Life Sciences. Experience: Should have minimum 5 years experience in identification of bird species, study of bird habits, knowledge of computer programmes like MS Office and excellent communication skill in English.

Job Description: The work involves extensive travel for field research study like bird monitoring, collection of information/data, preparation of reports, studying the bird habits, identification of bird species which are potentially hazardous to aircraft in and around aerodromes, evolving remedial measures, identificatin of bird - strike remnants, etc. Valid driving licence for 4 wheeler will considered additional qualification.

Age Limit: Upto 35 years. The appointment will be initially for a period of one year on contract basis.

Salary: upto Rs. 25,000/- p.m. People working in similar organization can also come on deputation for the duration of the project. Candidates fulfilling the above requirements may send their applications with detailed bio-data and expected salary within 10 days to:

Director, Bombay Natural History Society, Hornbill House, Shaheed Bhagat Singh Road, Mumbai 400023, www.bnhs.org

\section{Salim Ali Centre for Ornithology and Natural History (SACON)}

Anaikatty post, Coimbatore 641108 , Tamil Nadu

requires two Research Associates for its programme "Strengthening community conservation efforts in Nagaland: A Programme to impart technical support on biodiversity conservation and livelihood options to communities in Phek, Tuensang and Mon districts"

Age: below 35 years (as on 01.05.2007). Relexable up to five years in case of SC/ST; a consolidated monthly salary Rs. 19,500 (for $1^{\text {st }}$ year); Rs. 20,000 (for $2^{\text {nd }}$ year) and Rs. 20,500 (for $3^{\text {rd }}$ year).

\section{Duration: 3 years}

Eligibility: Ph.D in (1) Wildlife Biology/Zoology/Ecology/Environmental Sciences; (2) Botany/Plant Sciences. Those who have submitted their Ph.D thesis or are about to may also apply.

We are looking for young scientists who are capable of strenous fieldwork and interested in biodiversity conservation and working with local communities. Application on plain paper in the following format should reach the Director within 20 days from the date of the publication of the advertisement: (1) Name, (2) Date of birth, (3) address, (4) Educational qualifications with copies of the relevant document, (5) Details of experience, (6) List of publications, (7) A one-page write-up on candidate's field of research interest. SACON reserves the right of relaxing the above conditions for exceptional candidates.

For further details please refer the Employment News dated $28^{\text {th }}$ April 2007 